\title{
A deficiência e as concepções que conformam o campo da educação especial: permanências e rupturas em sua identidade
}

Disability and the conceptions conforming the field of special education: permanencies and ruptures in its identity

La discapacidad y las concepciones que conforman el campo de la educación especial: permanencias y rupturas en su identidad

\section{Sirleine Brandão de Souza}

Professora doutora da Universidade Federal de Minas Gerais, Belo Horizonte, MG, Brasil

E-mail: sirleinesouza@uol.com.br ORCID: https://orcid.org/0000-0003-0643-1322

Recebido em 07 de junho de 2021

Aprovado em 30 de outubro de 2021

Publicado em 18 de novembro de 2021

\section{RESUMO}

O presente artigo tem como objetivo analisar, por meio de artigos publicados no periódico Revista Brasileira de Educação Especial, no período compreendido entre os anos de 1992 e 2015, as concepções subjacentes ao conceito de deficiência, empregadas pelos pesquisadores do campo, por meio da caraterização do alunado que o compõe, marcadas por determinados espaços e tempos históricos. Os textos foram selecionados a partir de critérios definidos a priori e analisados tendo por base o referencial teórico bourdieusiano. Como resultados, pode-se averiguar diferentes concepções subjacentes ao conceito de deficiência compondo o campo da educação especial, conformando permanências e rupturas em sua identidade, demonstrando que, nem sua constituição, nem a constituição do saber que aí se produz e que institui a identidade de seu público são estáveis e inflexíveis, mas decorrem de movimentos distintos enredados pelos movimentos dos outros campos, especialmente o campo político, na medida em que este é o espaço em que as práticas educacionais se concretizam.

Palavras-chave: Deficiência; Educação Especial; Produção de conhecimento; Identidade.

\section{ABSTRACT}

This article aims to analyze, from the articles published in the journal Revista Brasileira de Educação Especial, between the years of 1992 and 2015, the concepts underlying the concept of disability employed by researchers in the field, through the characterization of the group of students who compose it, marked by certain spaces and historical times. The manuscripts were selected based on pre-established criteria and analyzed based on the Bourdieusian theoretical framework. As a result, the study identifies different conceptions underlying the concept of disability composing the field of Special Education, conforming permanencies and ruptures in its identity, demonstrating that neither its constitution nor the 
http://dx.doi.org/10.5902/1984686X66151

constitution of knowledge that is produced there, which institutes its audience's identity are stable and inflexible, but rather they stem from distinct movements enmeshed by movements from other fields, especially the political field, as the space in which educational practices take place.

Keywords: Disability; Special Education; Knowledge production; Identity.

\section{RESUMEN}

Este artículo tiene como objetivo analizar, a partir de los artículos publicados en la Revista Brasileira de Educação Especial, entre 1992 y 2015, los conceptos subyacentes al concepto de discapacidad empleado por los investigadores en el campo, a través de la caracterización del grupo de estudiantes que lo componen, marcado por ciertos espacios y tiempos históricos. Los manuscritos fueron seleccionados en base a criterios preestablecidos y analizados con base en el marco teórico bourdieusiano. Como resultado, el estudio identifica diferentes concepciones subyacentes al concepto de discapacidad que componen el campo de la Educación Especial, conformando permanencias y rupturas en su identidad, demostrando que ni su constitución ni la constitución del conocimiento que allí se produce, que instituye la identidad de su audiencia, son estables e inflexibles, sino que surgen de distintos movimientos enredados por movimientos de otros campos, especialmente el político, como espacio en el que se desarrollan las prácticas educativas.

Palabras clave: Discapacidad; Educación Especial; Producción de conocimiento; Identidad.

\section{Introdução}

Este artigo é parte de uma tese de doutorado defendida em 2018, que analisou o percurso histórico acerca da classificação e categorização do estudante da educação especial, e de como, tanto as condições com que se estabelece a identidade do sujeito com deficiência, como as marcas que lhe são imputadas, causam impacto mediante relações estabelecidas consigo mesmo, com os outros e com o espaço ocupado na sociedade.

De acordo com Goffman (1982), a sociedade tal como se organiza oferece os meios próprios para categorizar as pessoas em decorrência de seus atributos. Atribui-se às pessoas uma identidade social virtual, que pode ou não corresponder à identidade social real. Quando esse atributo não se encaixa na categoria definida como normal, inflige-se, então, um estigma, como algo depreciativo. O estigma é "a situação do indivíduo que está inabilitado para a aceitação social plena" (GOFFMAN, 1982, p. 7).

Bueno (2001) ressalta que no transcurso de diferentes momentos históricos, a produção da identidade do anormal se constituiu tendo em vista não a simples presença de uma diferença, mas o que essa diferença pode acarretar no processo de produção e desenvolvimento daquele determinado agrupamento social e de suas características de 
http://dx.doi.org/10.5902/1984686X66151

sobrevivência. Sendo assim, não é o simples fato de possuir uma diferença que por si só já constitui a identidade do sujeito, mas as relações estabelecidas entre esta e a sociedade que o abarca.

A distinção de quem é normal ou anormal, é feita tendo por base alguns critérios definidos na e pela própria sociedade. Entretanto, as diferenças entendidas como anormalidades têm concepções diferentes a depender do momento histórico, assim, o fato de que o sujeito caracterizado como deficiente, excepcional, com necessidades educativas especiais, público-alvo da educação especial, se insere em dada sociedade e que, assim, carrega as marcas da constituição que o enreda, que faz com que tenha ou não possibilidades para além de sua condição física, biológica ou psíquica.

Dessa forma, as concepções amplamente divulgadas a respeito da deficiência, inclusão, educação especial, necessidades educativas especiais por intermédio dos discursos produzidos no campo da Educação e, mais precisamente da Educação Especial, são essenciais de serem analisados, uma vez que os discursos se constituem como fontes privilegiadas das práticas e teorias no campo, influenciando as políticas e ações voltadas para esta população, bem como também sofrem suas influências.

Essas influências podem se dar de diferentes formas, uma vez que cada espaço social determina um tipo de disputa a ser travada na busca pela legitimação de um discurso.

Ao analisar os conceitos que fazem parte do campo da Educação Especial, eleitos como constitutivos do argumento da especialização e que compõem as políticas para os chamados sujeitos com necessidades educativas especiais, ou mais recentemente públicoalvo da educação especial, bem como as caracterizações e classificações dessa população como expressão de lutas simbólicas que se travam em determinado campo, necessariamente a discussão percorre a constituição histórica na qual os conceitos são moldados e sua relação explícita ou implícita como instrumentos de ação político-social.

Concebe-se, nesse quadro, a linguagem como mediação entre o ser humano e a realidade. A relação linguagem-pensamento-mundo não se dá de forma unívoca e linear, sem contradições e de forma natural - antes é um jogo que está imbricado em relações de poder, em lugares de saber ocupados e legitimados, em um lugar objetivamente ocupado e, portanto, campo de luta simbólica.

De acordo com Williams (2009), a linguagem como consciência prática impregna e está impregnada das atividades sociais, ocorrendo dentro de sociedades ativas que se transformam, transformando dessa forma as experiências. A linguagem, dessa maneira, se 
http://dx.doi.org/10.5902/1984686X66151

constitui por meio da existência social e material entre indivíduos reais em atos de comunicação.

Ademais, pensar o discurso, sua produção e circulação, faz-se necessário considerar que, tal discurso se produz no interior de um campo em contextos e mercados particulares e que "[...] as propriedades desses mercados portam produtos linguísticos de um determinado valor [...]" (BOURDIEU, 1991, p. 32 - tradução nossa).

Assim, o campo científico da Educação Especial, especificamente na caracterização e classificação de sua população, expressa lutas efetivadas por meio de discursos que podem se transformar em hegemônicos, dadas as condições de suas produções e dos lugares ocupados na distribuição de capital detido pelos agentes ou instituições em diferentes campos, mantida íntima relação com o campo político.

Em trabalhos anteriores, realizou-se análise sobre a utilização dos termos necessidades educacionais/educativas especiais, necessidades especiais e público-alvo da educação especial, os quais, como foi indicado, também se utilizavam, para defini-los, do termo deficiência.

Nesse sentido, parece evidente que, se o universo da educação especial tem sido motivo de disputas e controvérsias, não há qualquer dúvida de que ele abarca os alunos com deficiência.

Por outro lado, embora haja unanimidade de que esses sujeitos compõem o alunado da educação especial, cabe inquirir se o objeto científico construído (aluno com deficiência) tem o mesmo significado para todos os estudiosos.

Dessa forma, pretendeu-se analisar as concepções acerca de deficiência produzidas e publicadas em artigos na Revista Brasileira de Educação Especial entre os anos de 1992 e 2015.

Para essa análise, recorreu-se ao levantamento dos artigos na RBEE desde a sua criação em 1992. A justificativa para tal escolha se deu por ser esse periódico um dos mais importantes nacional e internacionalmente, por publicar trabalhos desde a década de 1990, permitindo uma análise histórica e por congregar grande parte dos pesquisadores do campo.

O levantamento se deu por meio dos seguintes critérios: corresponder ao período de 1992 a 2015; abordar discussão ampla sobre educação especial; ser redigido em língua portuguesa e conter em seu corpo textual os descritores deficiência e/ou deficiente. 
http://dx.doi.org/10.5902/1984686X66151

Selecionou-se noventa textos correspondentes aos critérios descritos. Dentre esses, elegeu-se aqueles que apresentavam uma discussão conceitual, nos quais os autores apontaram concepções sobre a deficiência ou o sujeito deficiente, o que redundou em dezesseis textos, organizados em três diferentes perspectivas de entendimento.

Um primeiro conjunto tem como perspectiva fundamentos de base estritamente biológica, definindo a deficiência por meio de manifestações puramente orgânicas localizadas no indivíduo, para o qual devem ser pensadas formas de atendimento que lhe garanta capacitação para a vida cotidiana, já que apresenta características que escapam à normalidade e que se constituem foco de atenção dessa abordagem.

Um segundo conjunto compreende a deficiência como mera diferença, alegando a igualdade de todos os indivíduos, indicando que as diferenças são constituintes do ser humano, cabendo à sociedade além de respeitá-las e aceitá-las, também promovê-las como forma de inclusão de todos.

E por fim, um terceiro conjunto que tem como perspectiva a relação entre a deficiência e o espaço social, fundamentando-se na complexidade existente entre o sujeito em determinados e específicos momentos históricos e a sociedade organizada por meio de regras e normas, que redundam em diferentes significações das deficiências e dos deficientes.

Na medida em que a utilização desse termo perpassa todo o período, mesmo quando outros termos eram considerados mais adequados (excepcionalidade e necessidades educacionais especiais), a categorização primeira será a de reunião de artigos que expressem essas três tendências e, dentro delas, uma distribuição que possa abarcar diferentes períodos.

\section{A deficiência expressa por uma visão orgânica}

Esse conjunto de textos procura demonstrar uma visão da deficiência calcada exclusivamente no sujeito e em suas limitações, com o foco direcionado exatamente para a falta ou a dificuldade.

O corpus que constituiu o conjunto de textos selecionados foi o seguinte:

Anache (1996); Bergo et. al. (2001); Ramos e Alves (2008);

Anache (1996) se refere a esse alunado como "indivíduos portadores de deficiência: física, mental, auditiva e visual [...]", acrescentando que 
http://dx.doi.org/10.5902/1984686X66151

[...] o incremento tecnológico permite a simplificação e objetivação do trabalho e o portador de deficiência pode ser treinado à execução de trabalho simples e, consequentemente, ser incorporado ao processo produtivo [...] (ANACHE, 1996, p. 119).

O trecho citado faz parte de um texto que aborda a relação entre pessoas com deficiência e mercado de trabalho, e cujo objetivo é o de analisar as condições específicas dessas pessoas que pudessem interferir em sua contratação e na forma de integração ao mercado de trabalho. O que a pesquisa que redundou no presente artigo objetivava, era verificar qual tipo de limitação as diferentes deficiências causavam em relação às exigências do mercado de trabalho.

Já em momento posterior, em outro artigo, publicado em 2001, Bergo, et al. apresentam resultados de pesquisa sobre a sexualidade do deficiente mental, o que fez com que valorizassem o auxílio proporcionado pelos diagnósticos realizados por especialistas que, segundo elas, poderiam contribuir para um conhecimento mais qualificado, tanto por pais quanto por professores, para lidarem com manifestações de sexualidade por parte desses alunos:

O primeiro passo para a identificação das dificuldades infantis, especialmente na detecção de deficiências, bem como o esclarecimento das peculiaridades do aluno portador de necessidades educacionais especiais, [passa] pelas avaliações de equipes multidisciplinares, compostas do diagnóstico médico, fonoaudiológico, psicológico, assistencial - no caso das escolas da rede pública- e, especialmente, a pedagógica (BERGO et al., 2001, p. 29-30).

Essa centralidade fica ainda mais evidente no decorrer de todo o artigo, em que as autoras procuram comprovar que o conhecimento sobre as limitações específicas das deficiências oferece subsídios importantes para sua superação:

Vários autores apontam para o fato de que se os profissionais que lidam com as crianças com desenvolvimento alterado, ou com seus pais, devem ser treinados para identificarem as dificuldades, tanto quanto as oportunidades naturalmente surgidas, para que se possa efetivamente aproveitar de tais situações para poder utilizar procedimentos funcionais de modelagem e de enfraquecimento de respostas indesejáveis [...] (BERGO et al., 2001, pp. 3031).

Assim, o que caracteriza essa produção é a busca de superação de determinadas perspectivas pouco qualificadas sobre a sexualidade desses indivíduos, procurando oferecer subsídios para que o meio social pudesse lidar de forma mais satisfatória com essas manifestações. 
http://dx.doi.org/10.5902/1984686X66151

O último texto selecionado foi o de Ramos e Alves (2008), que investigaram a atuação do fonoaudiólogo junto a crianças com deficiência inseridas na educação escolar (regular ou especial), na medida em que partem da premissa de que a escola,

[...] ao oferecer oportunidades para alunos com necessidades especiais, informe-se e oriente-se com profissionais especializados da Educação e da Saúde sobre as especificidades e instrumentos adequados para que o aluno encontre ali um ambiente adequado e que the proporcione o maior e melhor aprendizado possível (RAMOS e ALVES, 2008, p. 236).

Verifica-se o esforço que as autoras realizaram no sentido de qualificar o trabalho específico do profissional para superação de características individuais limitadoras, embora continuem enfatizando seus aspectos intrínsecos:

O fonoaudiólogo é capaz de criar condições favoráveis e eficazes para que as capacidades de cada aluno possam ser exploradas ao máximo, não no sentido de eliminar problemas, mas sim baseado na crença de que determinadas situações e experiências podem facilitar e incrementar o desenvolvimento e a aprendizagem (RAMOS e ALVES, 2008, p. 237).

A inserção acadêmico-profissional das autoras, indica uma outra peculiaridade que merece ser mencionada: o fato de o primeiro artigo ser de autoria de pesquisadora reconhecida na área educacional, com atuação acadêmica abrangente e prolongada, a segunda de autoria de pesquisadoras do campo da psicologia e a terceira, da fonoaudiologia, mostra que a perspectiva centrada nas limitações das deficiências não é prerrogativa de estudiosos do campo da saúde, embora ela aí possa prevalecer.

Ou seja, a focalização nas limitações é uma perspectiva que não só se dissemina por diversos campos de conhecimento, como é uma abordagem que merece ser levada em consideração, na medida em que distintas deficiências ocasionam limitações específicas e diferenciadas.

\section{A deficiência encarada como mera diferença}

Esse conjunto de textos demonstra uma perspectiva de que a deficiência deve ser entendida como uma diferença entre tantas outras que o ser humano possui, cabendo à sociedade aceitá-las, respeitá-las e mais do que isso, segundo Abramowicz (2001) "produzir diferenças".

Assim, o corpus selecionado para essa discussão é o seguinte:

Abramowicz (2001); Rechneli et. al. (2008); Cardoso-Buckley (2011). 
http://dx.doi.org/10.5902/1984686X66151

O primeiro texto selecionado para essa análise é o de Abramowicz (2001), em que a autora enfatiza essa perspectiva da seguinte maneira:

O que fazem os adultos entre si, com as crianças, com os pais, na sua vida? O que fazem os adultos com os negros? Com os pobres? Com os deficientes? O que faremos com os diferentes? Em síntese, a pergunta que está colocada, é o que pretendemos fazer com "o outro", "com o estrangeiro?" É preciso que as diferenças sejam o mote da ação pedagógica, produzir diferenças, não tolerá-las ou apenas aceitá-las (ABRAMOWICZ, 2001, p. 8).

Verifica-se, por esse excerto, que as deficiências foram equiparadas a outras categorias de diferenças, como os negros e os pobres. Ou seja, as limitações específicas das deficiências deixam de ser consideradas, na medida em que é preciso produzi-las.

Essa perspectiva faz com que a autora não reconheça possíveis limitações que a façam colocar no mesmo patamar indivíduos com características distintas:

\begin{abstract}
Alguns poderão ficar horrorizados, como tais seres tão imperfeitos, "mongóis" dirão alguns, podem trazer partículas de um povo novo? Como os loucos com suas desrazões, podem trazer tais partículas? Como os pobres, que são aqueles quem, aparentemente, nada tem, tem algo deste povo novo? Os Sem teto? Os Sem terra? Ficamos horrorizados só em pensar, incluídos que estamos nos modelos de sentido, de beleza, de riqueza, de saúde, embevecidos de nossa perfeição, pois vivemos atolados e mal percebemos a perversidade embutida na publicidade desta estética veiculada pela maquinaria midiática, pela gorda saúde dominante, diria Deleuze, destes corpos magérrimos e sarados, por exemplo. Mal começamos a compreender o que são diferenças. Incluir para quê? É uma pergunta que necessitamos fazer. O que pretendemos fazer com suas diferenças? (ABRAMOWICZ, 2001, p. 4).
\end{abstract}

Em seu texto, a autora deixa claro que sua discussão sobre inclusão não deve ser pautada pela defesa da exclusão das crianças do ensino regular, muito menos por seu enclausuramento em instituições segregadas, "o que importa entender e responder é, o que pretendemos fazer com as diferenças que as crianças trazem quando propomos a inclusão"? (ABRAMOWICZ, 2001, p. 5).

Essa perspectiva redunda em um corolário que implica a generalização de que toda e qualquer ação com caráter normativo seja criticada:

[...] sob o pretexto de acolher as diferenças não estamos propondo aboli-las? Ao propor trazer as crianças para essa escola que conhecemos, que trabalha o homogêneo, o disciplinamento do corpo, da palavra e da voz, o que pretendemos ao trazê-los para essas instituições?

O que a nossa cultura faz com o louco, com o deficiente, com o portador de qualquer diferença? $O$ que parece que nossa cultura realiza é o desejo que desapareçam da nossa frente, não suportamos a estranheza, o outro, o estrangeiro, a alteridade radical. Quais os espaços sociais nos quais estão presentes essas crianças e esses jovens? Onde eles estão? Onde os vemos? O que propomos para eles? Quais deles fazem parte das nossas vidas? (ABRAMOWICZ, 2001, p. 5). 
http://dx.doi.org/10.5902/1984686X66151

Como consequência, a proposição educativa decorrente é a afirmação de que não se deve:

[...] nem aceitar, muito menos tolerar diferenças, mas sim produzir diferenças. Há uma incessante forma de vida que são produzidas pelos diferentes que é preciso estar atento para aproveitar. Ou seja, a educação só será inclusiva se se prestar a exterioridade, ou seja, se "estes novos alunos" envergarem a escola com suas diferenças, e a modificarem. E ao mesmo tempo, teremos uma educação inclusiva quando tais crianças e jovens puderem passear a céu aberto com toda a exuberância de suas diferenças (ABRAMOWICZ, 2001, pp. 8-9).

Rechineli, et al. (2008), por meio de um estudo na área da Educação Física, tiveram como objetivo "analisar o ser humano classificado por seu corpo deficiente no passado, eficiente no presente e diferente no futuro" (RECHINELLI et al., 2008, p. 293).

Nesse sentido, argumentam que:

[...] refletir sobre a aceitação do diferente é peça fundamental para que tudo possa ser estabelecido e/ou construído. É preciso re-significar a diferença/deficiência, e para tanto, há que se des-adjetivar o substantivo diferença: ser diferente não é ser melhor ou pior; a diferença/deficiência simplesmente é (RECHINELI et al., 2008, p. 294).

Ao acrescentar, sob esta óptica, a perspectiva de que somos todos diferentes, parecem não reconhecer as limitações que as deficiências efetivamente acarretam às atividades humanas: "no passado por ser deficiente e improdutivo, observado no presente como eficiente e capaz e, finalmente, descoberto como diferente, como todos os seres humanos o são [...]" (RECHINELI et al, 2008, p. 306).

Sob esta argumentação, concluem que a

Educação Física para as PD com base nos princípios da Motricidade Humana que, ao estudar o ser humano que se movimenta intencionalmente na direção de sua autosuperação, não classifica esse ser humano em deficiente ou eficiente, pois o corpo pode ser classificado de deficiente, mas a corporeidade não (RECHINELI et al., 2008, p. 308).

Em 2011, Maria Cecília Cardoso-Buckley teve publicado seu artigo no qual ela entende que

Com uma abordagem inclusiva, abre-se o diálogo para o reconhecimento das diferenças de todos e passa a ser aceitável o que anteriormente era tabu todos os educandos (portanto todas as pessoas...) têm diferenças, talentos particulares e necessidades específicas que devem ser considerados e atendidos. Se levarmos esta afirmação às suas últimas consequências - e os mais ousados o afirmamos - chega-se a uma visão da pessoa humana onde, com suas diferenças, todos, sem exceção, são únicos, insubstituíveis, trazendo suas deficiências e seus dons que apontam necessidades que, embora sejam variadas em tipo, número e grau, requerem reconhecimento e algum tipo de ação por parte da comunidade. 
http://dx.doi.org/10.5902/1984686X66151

\title{
$[\ldots]$
}

\begin{abstract}
Este reconhecimento traz inúmeras consequências, nem sempre fáceis de defrontarmos. A deficiência não é mais uma característica somente das pessoas tradicionalmente diagnosticadas como tal, assim como ter dons não é um atributo das pessoas tradicionalmente consideradas "típicas". Ter deficiências e ter dons são predicados inerentes ao ser humano - qualquer ser humano (CARDOSO-BUCKLEY, 2011, p. 19)
\end{abstract}

A autora critica a inclusão que tem como perspectiva a busca por uma padronização de comportamento, o que pode acarretar o aniquilamento "da unicidade do indivíduo com o seu direito à liberdade e à escolha" (CARDOSO-BUCKLEY, 2011, p. 20).

Assim, a autora conclui que:

\begin{abstract}
É nesta comunidade humana, perplexa e cheia de dicotomias e incoerências, com diferentes tipos de visão da pessoa humana, que buscamos a inclusão. São os membros desta comunidade que chamamos a abraçar o princípio de acolher as diferenças - reconhecendo e respeitando cada pessoa como ela é, com seu valor intrínseco, com todos os seus dons e suas deficiências - e todas as consequências advindas deste reconhecimento e respeito [...] (CARDOSO-BUCKLEY, 2011, p. 21).
\end{abstract}

Se o primeiro texto (Abramowicz, 2001) aponta que não existe a deficiência, mas sim diferenças, e que a sociedade, ao invés de tentar incluir as pessoas com deficiência, deve, antes, propor que se trabalhe no sentido de incentivar e produzir cada vez mais as diferenças, o segundo (Rechineli, et al., 2008) admite as limitações causadas pela deficiência, tratando-as como diferenças que devem ser observadas e integradas à vida na sociedade; este terceiro texto (Cardoso-Buckley, 2011) enfatiza o fato de que todos têm deficiência, ou ainda, de que a deficiência é inerente ao ser humano.

\section{A relação deficiência e espaço social}

Neste tópico, buscou-se organizar os textos que evidenciam a relação entre a deficiência e o espaço social. Apontam que a deficiência não se localiza somente no sujeito, mas que fatores externos - sociais, emocionais e educacionais - influenciam e são influenciados por tal fenômeno.

Embora os textos constituam um único conjunto, possuem peculiaridades que os diferenciam, na medida em que uma primeira abordagem considera que não só as características individuais da deficiência e suas limitações, mas também os fatores externos, implicam diferentes trajetórias constitucionais do sujeito. Ao passo que uma segunda abordagem, embora também procure estabelecer relações entre a deficiência e o 
http://dx.doi.org/10.5902/1984686X66151

espaço social, possua seu foco sobre as consequências que elas acarretam para a sua inserção social.

O corpus que compõe esse tópico é o seguinte:

Omote (1994); Omote (1996); Mrech (1999); Maia (2001); Williams (2003); Leite (2004); Michels (2005); Dallabrida (2007); Abe e Araújo (2010); Silva e Meletti (2014).

O primeiro texto desse conjunto, de Sadao Omote publicado em 1994, aponta que:

São infindáveis as diferenças entre as pessoas [...]. Interessam [...], sobretudo aquelas que, numa determinada circunstância e num determinado grupo, se evidenciam pela significação, ainda que esta não seja consensualmente endossada pelas pessoas [...] (OMOTE, 1994, p. 65).

Esse autor destaca a relação entre deficiência e diferença, mas não qualquer diferença. A diferença se refere àquela que causa um alto grau de estranhamento, ou seja, se relaciona com aquilo que não é comum em determinada sociedade num dado período, como pode ser evidenciado pelo seguinte excerto:

[...] estas devem ser consideradas no contexto de um problema mais geral da Psicologia, que é o das diferenças individuais. No entanto, as deficiências não são, do ponto de vista psicológico, diferenças individuais quaisquer. Aquelas têm, necessariamente, alguma significação de desvantagem e de descrédito social. Portanto, são determinadas diferenças às quais foram atribuídas determinadas significações de desvantagem e que levam os seus portadores a serem desacreditados socialmente (OMOTE, 1994, p. 66).

Compreende-se, por meio dessa citação, a visão de que uma diferença individual não é em si mesma vantajosa ou desvantajosa, e nesse sentido, a deficiência depende muito da relação estabelecida entre o sujeito e o outro, e desses com o espaço social no qual ocorre tal situação:

\begin{abstract}
As diferenças individuais são características apresentadas por pessoas específicas. Na medida em que algumas delas se destacam e lhes são atribuídas significações de desvantagem e de descrédito social, essas diferenças não podem mais ser vistas tão somente como variações nas características inerentes a algumas pessoas. É necessária uma linguagem de relações e não de atributos para serem descritas e estudadas essas diferenças (deficiências) (OMOTE, 1994, p. 66).
\end{abstract}

Entende-se, portanto, por meio desse excerto, que o autor considera que uma situação de desvantagem causada por algum tipo de deficiência não se dá por si só, mas depende - a desvantagem - da relação estabelecida entre a pessoa com deficiência, o outro e o próprio espaço social.

Mais adiante, Omote (1994) assinala a ambiguidade relativa à definição de critérios ou de padrões que justificariam a deficiência e a não-deficiência: 
http://dx.doi.org/10.5902/1984686X66151

$\mathrm{Na}$ realidade, não se trata apenas de uma questão de definir e estabelecer esse critério, mas também a de decidir aplicá-lo e de se criarem nas pessoas expectativas nesse sentido. A questão da escolha de um dado critério ou padrão depende das forças sociais prevalecentes no grupo ou organização em cujo interior a deficiência adquire um particular significado e se constitui num importante problema. Portanto, trata-se de uma questão antes política que lógica ou científica (médica, psicológica ou educacional) (OMOTE, 1994, p. 67).

A identidade de deficiente ou não-deficiente, para esse autor, é construída socialmente, nas relações estabelecidas entre pessoas e suas expectativas. Segundo ele, "a deficiência não pode ser vista como uma qualidade presente no organismo da pessoa ou no seu comportamento" (OMOTE, 1994, p. 67).

Em 1996 o mesmo autor indicou que:

O estudo que focaliza somente o indivíduo deficiente dificilmente pode ser considerado um estudo da deficiência; pode sê-lo da patologia de que ele é portador. Essa patologia ou as suas consequências somente adquirem o sentido de deficiência perante uma determinada audiência munida de um conjunto de critérios para julgar a adequação ou inadequação de atributos e comportamentos, em função de expectativas normativas fortemente estabelecidas na coletividade, e para interpretar os atributos e comportamentos que estão de conformidade com tais expectativas normativas (OMOTE, 1996, p. 130).

Nessa publicação de 1996, a conceituação sobre deficiência, elaborada pelo autor, parece ficar mais evidente:

A conceituação de qualquer deficiência [...] precisa levar em conta os fenômenos de natureza anátomo-fisiológica (lesões, malformações, disfunções, etc.), somato-psicológica (manifestações psicológicas resultantes de alterações constitucionais) e psicossocial (autopercepção, identidade pessoal, autoconceito, etc.) manifestados pela pessoa deficiente, além das reações das audiências, particularmente dos outros significativos e das agências de controle. As relações interpessoais e sociais entre o deficiente e suas audiências constituem elementos importantes para a construção e legitimação da deficiência sobreposta à pessoa identificada como deficiente (OMOTE, 1996, p. 131).

Acrescenta, dessa maneira, que:

[...] Para se compreender o que é a deficiência, não basta olhar para aquele que é considerado deficiente, buscando no seu organismo ou no comportamento atributos ou propriedades que possam ser identificados como sendo a própria deficiência ou algum correlato dela. Precisa olhar para o contexto no qual, com o seu sistema de crenças e valores e com a dinâmica própria de negociação, alguém é identificado e tratado como deficiente. Tal contexto condiciona o modo de tratamento da pessoa deficiente e por este é condicionado (OMOTE, 1996, p. 133).

Assim, desse ponto de vista, a deficiência parece depender das interpretações no processo de interação entre os sujeitos. 
http://dx.doi.org/10.5902/1984686X66151

A ideia de que a identidade de deficiente é constituída por meio das relações sociais, permeia outras produções no decorrer do período selecionado para análise. Assim, em 2007, foi publicado um texto no qual Adarzilse Mazzuco Dallabrida ressalta:

Partindo do pressuposto de que o conceito de deficiência é uma construção social, para além das determinações biológicas, ou seja, de que a deficiência orgânica não se constitui na única característica para a produção da identidade dos sujeitos, mas sim que, sem negar que estas características são marcas fundamentais na construção dessas identidades, não pode prescindir dos processos sociais pelos quais eles passam e são fatores determinantes para a sua humanização (DALLABRIDA, 2007, p. 460).

A autora indica, para além de uma "audiência" generalizada, que na produção da identidade do deficiente os aspectos relacionados à classe social são importantes de se destacar:

A relatividade entre possibilidades e limites na integração social de indivíduos deficientes, dentro do padrão esperado de determinada sociedade, como por exemplo, escolaridade e atividade profissional, parece estar relacionada mais com o meio sócio econômico do qual o mesmo faz parte, do que com as específicas dificuldades que a deficiência poderia ocasionar.

$[\ldots]$

As oportunidades de desenvolvimento da autonomia e da individualidade, que fazem parte do processo de humanização, são oferecidas de forma desigual através de diversas maneiras de escolarização. Com os deficientes, a "marca negativa" parece suplantada nos estratos superiores da sociedade de classes, pelo fato de terem maior acesso à educação de qualidade e, consequentemente, à integração social (DALLABRIDA, 2007, p. 462).

Assim, acrescenta à discussão importante aspecto relacionado às posições ocupadas pelos sujeitos nas classes e frações de classes, o que cria diferentes formas de estar e se relacionar com o mundo real.

Embora em número bastante reduzido, nos últimos anos alguns pesquisadores têm incluído indicadores de posição social, raça e gênero em suas pesquisas, como é o caso do artigo de Silva e Meletti (2014), em que se realizou análise das políticas educacionais por meio de indicadores estatísticos contidos no Censo Escolar e na Prova Brasil (BRASIL. MEC. INEP), dos anos de 2007 e 2008.

Embora não haja uma definição explícita da inclusão desses elementos na constituição do fenômeno social da deficiência, o simples fato de que eles compõem o conjunto de indicadores das políticas de educação especial, evidenciam sua incorporação como elemento a ser investigado porque não conhecido, de tal forma que, em todas as análises, dois dos cruzamentos fundamentais da coleta foram o sexo e a raça/etnia, com a 
http://dx.doi.org/10.5902/1984686X66151

constatação da prevalência do número de alunos do sexo masculino e brancos, o que evidencia a desigualdade de incorporação, pela educação especial, de alunas do sexo feminino e negras.

O artigo de Maria Helena Michels, publicado em 2005, em que analisa os currículos de duas modalidades de cursos de formação de professores da Educação Especial da Universidade Federal de Santa Catarina (regular e emergencial), acrescenta a essa vertente a crítica de que, apesar de diferenças significativas entre as duas modalidades de formação, ambas são calcadas na perspectiva da

[...] manutenção da compreensão do fenômeno educacional relacionado ao aluno considerado deficiente, pela base biológica e, de maneira mais acentuada, pela Psicologia. A reiteração dessas bases de conhecimento retira da Educação a compreensão da deficiência e da própria ação pedagógica como fato social. Sob os auspícios do modelo médicopsicológico, o aluno é responsabilizado pelo seu sucesso ou fracasso escolar, os quais são explicados pelas marcas de deficiência. Tal visão tem sido hegemônica, encobrindo a compreensão segundo a qual os sujeitos se constituem nas e pelas relações sociais. Como superar, então, o processo de exclusão escolar? Como pensar a inclusão como objetivo dessas formações de professores? (MICHELS, 2005, p. 270).

Com base nas contribuições do sociólogo norte-americano Thomas Skrtic, a autora considera que a restrição às bases biológicas e psicológicas que caracterizam ambos os cursos, expressavam a perspectiva positivista que desconsidera as relações sociais como elemento constituinte da deficiência.

Assim, mesmo reconhecendo que ocorreram avanços na atuação prática com base nessa perspectiva, ela concorre para que os alunos continuem sendo encarados somente pelas marcas intrínsecas de suas deficiências, com praticamente absoluto desconhecimento dos fatores sociais que, junto com as características biológicas e psicológicas, irão constituir suas identidades sociais.

Por meio dos textos citados, percebe-se a relação entre a deficiência e o espaço social, fundamentando-se na complexidade existente entre o sujeito em determinados e específicos momentos históricos, e a sociedade, o que evidencia que o espaço social é constitutivo da deficiência.

Embora os cinco textos corroborem essa perspectiva, ainda assim há algumas peculiaridades entre eles: os dois primeiros textos, de autoria de Omote (1994 e 1996), apreendem o espaço social como constitutivo da deficiência, na medida em que abordam aspectos de como a pessoa com deficiência lida com a diferença e a atribuição de significados pelos outros, ou seja, pela audiência, destacam que a deficiência não está na 
http://dx.doi.org/10.5902/1984686X66151

pessoa, embora reconheçam suas especificidades, mas nas relações e interpretações estabelecidas entre o sujeito e o espaço social.

O terceiro e quarto textos, de Dallabrida (2007) e Silva e Meletti (2014), acrescentam outras categorias de análise como marcas significativa na constituição da identidade das pessoas com deficiência.

E o quinto texto, de Michels (2005), aborda a crítica referente às bases que sustentam a educação especial, afirmando que não só características psicológicas e biológicas constituem a identidade social do sujeito, mas também os aspectos sociais.

Os textos a seguir, embora também procurem estabelecer relações entre a deficiência e o espaço social, têm como foco as consequências que elas acarretam para sua inserção social.

Assim, ainda em 1999 (MRECH, 1999, p. 128), o artigo publicado na RBEE no qual, embora tenha designado o deficiente como "[...] indivíduo que apresenta deficiência de qualquer tipo: física, auditiva, mental ou visual", apontou também que a deficiência por si só não gera as dificuldades.

A partir de um novo modelo de análise referente às deficiências, a autora apontou que o contexto de inclusão "surgiu devido à necessidade de se trabalhar, no campo educacional, de forma menos estigmatizadora, de maneira que fosse comum, unindo tanto os alunos deficientes quanto os normais" (MRECH, 1999, p. 132). De acordo com essa autora,

[...] aos poucos a Educação Inclusiva acabou estruturando nova forma de olhar a Educação. Uma forma na qual ela não segregasse mais os sujeitos, independentemente do fato deles serem deficientes ou não (MRECH, 1999, p. 133).

Assim,

[...] não basta apenas identificar a deficiência que a criança apresenta; é preciso lidar também com a inclusão dessa criança dentro do contexto escolar [...] para que a criança possa realmente ter as suas necessidades educativas especiais atendidas (MRECH, 1999, p. 138).

A autora indicou que se faz necessário mudar o foco de um "[...] modelo de deficiência tradicional e a necessidade de difusão de um novo modelo de deficiência centrado em abordagem mais social" (MRECH, 1999, p. 141).

Em síntese, para ela a nova perspectiva política da educação - a inclusão escolar foi a desencadeadora de uma nova perspectiva na concepção da deficiência e não o inverso, tal como indicado nos textos anteriores, de que as relações sociais eram elementos constituintes da deficiência. 
http://dx.doi.org/10.5902/1984686X66151

No que se refere às consequências sociais da deficiência, perspectiva semelhante à de Mrech é a de Maia (2001, p. 38), quando argumenta que, com frequência,

[...] os aspectos limitadores não estão na deficiência em si, mas nas barreiras psicológicas que dela derivam: por exemplo, tédio pelas restrições físicas e/ou isolamento social, depressão, insegurança ou baixa auto-estima. Outras vezes, são barreiras físicas que limitam a pessoa deficiente ou criam e alimentam barreiras psicológicas (falta de aptidão verbal, remédios, higiene pessoal, maneirismos) e ainda podem ser barreiras sociais como isolamento, falta de convívio social entre amigos e preconceitos sociais [...] (MAIA, 2001, p. 39).

Outro artigo que fornece elementos interessantes é o de autoria de Williams (2003), que, depois de uma década no Canadá, no retorno ao Brasil em 1999, embora tenha se dedicado ao estudo da violência doméstica, publicou artigo na RBEE em que procurou aliar suas duas experiências. Assim, além de procurar estabelecer relações entre a ocorrência da deficiência e a violência doméstica, considerou que o sujeito com deficiência se encontrava em uma relação desigual de poder, fato que se intensifica "conforme a severidade de cada caso, sendo ampliada se o portador de necessidades especiais pertencer a um outro grupo de risco, como por exemplo, se for mulher ou criança". (WILLIAMS, 2003, p. 142).

Embora o texto citado não aprofunde a análise sobre a relação deficiência e gênero, sua simples designação acrescentou um aspecto até então pouco trabalhado no campo acadêmico da educação especial.

Nesse sentido, este artigo parece uma boa expressão da vertente que, sem desconsiderar as limitações próprias da deficiência, acrescenta um elemento importante para sua caracterização como sujeito social, qual seja, a diferença de gênero.

No ano seguinte, Leite (2004) se referiu ao meio social como elemento para a caracterização da deficiência da seguinte forma:

[...] a importância de entender o contexto social que o deficiente está inserido, notando que a deficiência não se restringe a um conjunto de limitações físicas, de origem orgânica. A audiência social acaba por produzir atitudes que irão estigmatizar o deficiente, deixando de garantir um conjunto de oportunidades para que ele se desenvolva como qualquer outro indivíduo pertencente a uma dada comunidade (LEITE, 2004, p. 134).

Nesse sentido, evidencia-se uma visão na qual a relação entre o sujeito com deficiência e o espaço social pode gerar consequências para seu desenvolvimento sem, no entanto, considerar essa relação como um dos elementos para a constituição de sua identidade. 
http://dx.doi.org/10.5902/1984686X66151

A influência do campo da medicina sobre a pesquisa educacional, pode ser exemplificada pela incorporação de determinadas publicações, de ordem prescricional, cujos componentes são incorporados como conhecimento já disposto e que não demandam investigação.

Um bom exemplo disso é a incorporação pela pesquisa educacional de elementos dispostos por documentos dessa natureza, como a Classificação Internacional de Funcionalidade, Incapacidade e Saúde - CIF (OMS, 2004).

Este documento, na medida em que acrescenta a questão da funcionalidade aos documentos normativos anteriores, considera que as:

[...] informações sobre a mortalidade (facultadas pela CID-10) e sobre as consequências na saúde (proporcionadas pela CIF) podem ser combinadas de forma a obter medidas sintéticas da saúde das populações. Isto permite seguir a saúde das populações e a sua distribuição, bem como avaliar a parte (OMS, 2004, p. 8).

Ao considerar que essa funcionalidade, além dos aspectos orgânicos, implica fatores contextuais, cujos componentes são os fatores ambientais e os fatores sociais, a CIF afirma que os primeiros "têm um impacto sobre todos os componentes da funcionalidade e da incapacidade e estão organizados de forma sequencial, do ambiente mais imediato do indivíduo até ao ambiente geral" (OMS, 2004, p 12).

Com relação aos fatores pessoais, indica que "também são um componente dos Factores Contextuais, mas eles não estão classificados na CIF devido à grande variação social e cultural associada aos mesmos" (OMS, 2004, p. 12).

Ou seja, a própria CIF reconhece as limitações que o campo da medicina tem para a classificação do que denominou como elementos mais específicos de diferentes sujeitos com limitações funcionais.

Mesmo assim, a CIF elenca uma série de elementos que constituem o que denominou de fatores sociais, que

[...] podem incluir o sexo, raça, idade, outros estados de saúde, condição física, estilo de vida, hábitos, educação recebida, diferentes maneiras de enfrentar problemas, antecedentes sociais, nível de instrução, profissão, experiência passada e presente, (eventos na vida passada e na actual), padrão geral de comportamento, carácter, características psicológicas individuais e outras características, todas ou algumas das quais podem desempenhar um papel na incapacidade em qualquer nível (OMS, 2004, p. 19).

Ora, se esse documento internacional elenca um expressivo número de elementos nessa categoria, mas afirma que não tem como classificá-los porque envolvem grande 
http://dx.doi.org/10.5902/1984686X66151

variação social e cultural, parece claro que esses elementos devem constituir focos de investigação de outras áreas - como as das ciências sociais - entre elas a pesquisa educacional.

No entanto, parte expressiva dos estudos em educação especial, que se reportam à CIF, incorporam esses elementos como componentes já conhecidos do ponto de vista teórico, como o de Abe e Araújo (2010), publicado na RBEE, em que reconhecem que "a restrição da participação do indivíduo em determinado contexto resulta de condições ambientais desfavoráveis ao desempenho" (OMS, 2004, apud ABE e ARAÚJO, 2010, p. 283).

No entanto, ao estabelecer as decorrências dessa constatação têm como premissa que já se tem conhecimento suficiente sobre as limitações impostas pelo meio social:

O conhecimento da funcionalidade e da incapacidade do aluno orienta a seleção de estratégias facilitadoras da participação, tendo-se como foco de intervenção não apenas o aluno com deficiência, mas também o ambiente da experiência" (ABE e ARAÚJO, 2010, p. 285).

Sobre esse conjunto de textos, foi possível evidenciar duas perspectivas distintas: uma que concebe o espaço social como constitutivo da deficiência, verificada por meio dos artigos de Omote (1994, 1996), Dallabrida (2007), Michels (2005) e Silva e Meletti (2014), e outra que aborda as consequências sociais da deficiência, por meio dos textos de Mrech (1999), Maia (2001), Williams (2003), Leite (2004) e Abe e Araújo (2010).

$\mathrm{Na}$ primeira abordagem, destaca-se que o espaço social intervém de forma significativa na constituição da deficiência. Ou seja, às marcas específicas da deficiência, outras como as de origem social, raça/etnia influenciam sobremaneira a constituição da identidade do sujeito com deficiência, embora esse tipo de pesquisa ainda seja produzido de forma muito restrita no periódico.

Referente à segunda abordagem, observa-se que a relação estabelecida entre a deficiência e o meio social gera consequências ao desenvolvimento do sujeito, embora desconsiderem essas relações na constituição da identidade social do deficiente.

Assim, os textos discorrem sobre aspectos relacionados às alterações que devem ser feitas no espaço escolar e na sociedade de forma geral, que levem em conta as limitações específicas dessa população, no sentido de favorecer a acessibilidade do alunado da educação especial, o que implicaria superação de barreiras arquitetônicas, de comunicação, sociais e atitudinais. 
http://dx.doi.org/10.5902/1984686X66151

\section{Considerações finais}

Por meio dos dados apresentados, destaca-se que embora a utilização de um conceito, parece evidenciar a univocidade de uma concepção, observa-se que essa é uma falsa ideia, na medida em que se indicou pelo menos três distintas formas de orientação a respeito de um único conceito - deficiência - acrescentado por uma variação numa mesma orientação, qual seja, a relação entre a deficiência e o espaço social.

Vale destacar a afirmação de Bourdieu et. al. (2010) em relação aos conceitos operatórios e sistemáticos. Para eles, os conceitos pensados de forma isolada não podem "resistir sistematicamente à lógica sistemática da ideologia" (BOURDIEU et al., 2010, p. 48).

Afirmam ainda a oposição entre os conceitos ditos operatórios e aqueles denominados sistemáticos, esses últimos somente compreendidos em sua inter-relação, uma vez que os conceitos operatórios, dada sua utilização unívoca não podem capturar a realidade.

Os conceitos e proposições exclusivamente definidos pelo seu caráter "operatório" podem limitar-se a ser a formulação logicamente irrepreensível de pré-noções e por esse motivo, são para os conceitos sistemáticos e proposições teóricas o que o objeto pré-construído é para o objeto construído. Por colocarmos a ênfase exclusivamente no caráter operacional das definições, corremos o risco de considerar uma simples terminologia classificatória como uma verdadeira teoria [...] (BOURDIEU et al., 2010, p. 48).

Assim, a análise de conceitos básicos utilizados no campo da Educação Especial, de forma contextualizada, contribui para a compreensão das lutas simbólicas que aí ocorrem, em busca de certa hegemonia intelectual. Essas lutas não devem ser ignoradas, na medida em que:

[...] as lutas que têm lugar no campo intelectual têm o poder simbólico como coisa em jogo, quer dizer, o que nelas está em jogo é o poder sobre um uso particular de uma categoria particular de sinais e, deste modo, sobre a visão e o sentido do mundo natural e social. Trata-se de um equívoco demasiado grosseiro a respeito de um ponto demasiado evidente para não ser de certo modo interessado, logo, estratégico (no sentido que eu dou a esta palavra), quer dizer, orientado, com toda a inocência, como em todas as formas de recusa de saber, pelos interesses ligados a uma posição (BOURDIEU, 2015, p. 71).

Ao analisar os conceitos que fazem parte do campo da Educação Especial, eleitos como constitutivos do argumento da especialização, componentes das políticas para os chamados sujeitos com necessidades educativas especiais, bem como as caracterizações e classificações dessa população como expressão de lutas simbólicas que se travam em determinado campo simbólico, necessariamente a discussão percorre a constituição 
http://dx.doi.org/10.5902/1984686X66151

histórica na qual os conceitos são moldados e sua relação explícita ou implícita como instrumentos de ação político-social.

Assim, as trocas linguísticas no interior das relações de comunicação são também relações de poder simbólico, atualizando a estrutura de força entre agentes e o campo (BOURDIEU, 1991), demonstrando que a linguagem é um instrumento de ação e de poder. Essas disputas não ocorrem somente como a expressão da superioridade de uma perspectiva sobre outra, mas trazem em seu bojo a própria concepção de mundo, de sociedade e de sujeito que nelas estão contidas.

As transformações subjacentes ao campo da educação especial demonstram que, nem sua constituição, nem a constituição do saber que aí se produz e que institui a identidade de seu público são estáveis e inflexíveis, mas decorrem de movimentos distintos - muitas vezes antagônicos, outras vezes complementares - enredados pelos movimentos dos outros campos, especialmente o campo político, na medida em que esse é o espaço em que as práticas educacionais se concretizam.

\section{Referências}

ABE, Patrícia Bettiol; ARAÚJO, Cássia Tibério. A participação escolar de alunos com deficiência na percepção de seus professores. Revista Brasileira de Educação Especial, São Paulo, n. 2, vol. 16, , mai./ ago. 2010. Disponível em: https://www.scielo.br/j/rbee/a/n8gHcqc7zbDQVmBsF8VWW7C/?format=pdf\&lang=pt. Acesso em: 13 fev. 2014.

ABRAMOWICZ, Anete. Educação inclusiva: incluir para quê? Revista Brasileira de Educação Especial, São Paulo, n. 2, vol. 7, 2001. Disponível em: https://www.abpee.net/revista-7-2.php. Acesso em 13 fev. 2014.

ANACHE, Alexandra Ayach. O deficiente e o mercado de trabalho: concessão ou conquista? Revista Brasileira de Educação Especial, São Paulo, vol. 4, 1996. Disponível em: https://www.abpee.net/pdf/artigos/art-4-10.pdf. Acesso em: 15 fev. 2014.

BERGO, Maria Stela de Araújo Albuquerque, et al. Diagnósticos e avaliações de alunos de classes especiais em Sergipe: investigações sobre a eficácia do Processo. Revista Brasileira de Educação Especial, São Paulo, n. 2, vol. 7, 2001. Disponível em: https://www.abpee.net/pdf/artigos/art-7-2-3.pdf. Acesso em: 20 fev. 2014.

BOURDIEU, Pierre. Langage et Pouvoir Symbolique. Cambridge, Grande-Bretagne: Polity Press, 1991.

BOURDIEU, Pierre; CHAMBOREDON, Jean-Claude, PASSERON; Jean-Claude. Ofício de sociólogo. Metodologia da Pesquisa em Sociologia. Tradução: Guilherme João de Freitas Teixeira. Petrópolis, RJ: Vozes, 2010. 
BOURDIEU, Pierre; CHAMPAGNE, Patrick. Os excluídos do interior. In: NOGUEIRA, Maria Alice; CATANI, Afrânio. (Orgs.). Escritos de Educação. 16 ed. Petrópolis, RJ: Vozes, 2015, p. 243-245.

BUENO, José Geraldo Silveira. A produção social da identidade do anormal. In: FREITAS, Marcos Cezar de. (Org). História social da infância no Brasil. 3 ed. rev. e ampl. São Paulo: Cortez, 2001, p. 163- 185.

CARDOSO-BUCKLEY, Maria Cecília de Freitas. Valores influenciando a visão do ser humano e pesquisa em educação especial: uma reflexão. Revista Brasileira de Educação Especial, São Paulo, n. especial, vol. 17, mai./ ago. 2011. Disponível em: https://www.scielo.br/j/rbee/i/2011.v17nspe1/. Acesso em: 20 fev. 2014.

DALLABRIDA, Adarzilse Mazzuco. As famílias e a classe especial em um colégio de elite. Revista Brasileira de Educação Especial, São Paulo, n. 3, vol. 13, set./ dez. 2007. Disponível em: https://www.scielo.br/j/rbee/i/2007.v13n3/. Acesso em: 20 fev. 2014.

GOFFMAN, Erving. Estigma. Notas sobre a manipulação da identidade deteriorada. 4 ed. Rio de Janeiro: Zahar Editores, 1982.

LEITE, Lúcia Pereira. Educador especial: reflexões e críticas sobre sua prática pedagógica. Revista Brasileira de Educação Especial, São Paulo, n.2, vol. 10, mai./ ago. 2004. Disponível em: https://www.abpee.net/pdf/artigos/art-10-2-1.pdf. Acesso em: 20 fev. 2014.

MAIA, Ana Claudia Bortolozzi. Reflexões sobre a educação sexual da pessoa com deficiência. Revista Brasileira de Educação Especial, São Paulo, n. 1, vol. 7, 2001. Disponível em: https://www.abpee.net/pdf/artigos/art-7-1-3.pdf. Acesso em: 13 mar. 2014.

MICHELS, Maria Helena. Paradoxos da formação de professores para a Educação Especial: o currículo como expressão da reiteração do modelo médico-psicológico. Revista Brasileira de Educação Especial, São Paulo, n. 2, vol. 11, mai/ ago. 2005. Disponível em: https://www.scielo.br/j/rbee/i/2005.v11n2/. Acesso em: 15 fev. 2014.

MRECH, Leny Magalhães. Os desafios da educação especial: o plano Nacional de educação e a universidade brasileira. Revista Brasileira de Educação Especial, São Paulo, vol. 5, 1999. disponível em: https://www.abpee.net/pdf/artigos/art-5-10.pdf. Acesso em: 13 mar. 2014.

OMOTE, Sadao. Deficiência e não-deficiência: recortes do mesmo tecido. Revista Brasileira de Educação Especial, São Paulo, vol. 2, 1994. Disponível em: https://www.abpee.net/pdf/artigos/art-2-6.pdf. Acesso em: 13 mar. 2014.

OMOTE, Sadao. Perspectivas para conceituação de deficiências. Revista Brasileira de Educação Especial, São Paulo, vol. 4, 1996. Disponível em: https://www.abpee.net/pdf/artigos/art-4-11.pdf. Acesso em: 13 mar. 2014.

OMS. Classificação Internacional de Funcionalidade, Incapacidade e Saúde.

Tradução e Revisão de Amélia Leitão. Lisboa: Direção Geral da Saúde, 2004. 
http://dx.doi.org/10.5902/1984686X66151

RAMOS, Alice de Souza; ALVES, Luciana Mendonça. A fonoaudiologia na relação entre escolas regulares de ensino fundamental e escolas de educação especial no processo de inclusão. Revista Brasileira de Educação Especial, São Paulo, n. 2, vol. 14, mai/ ago. 2008. Disponível em: https://www.scielo.br/j/rbee/i/2008.v14n2/. Acesso em: 22 fev. 2014.

RECHINELI, Andréa, et al. Corpos deficientes, eficientes e diferentes: uma visão a partir da educação física. Revista Brasileira de Educação Especial, São Paulo, n. 2, vol. 14, mai/ ago. 2008. Disponível em: https://www.scielo.br/j/rbee/i/2008.v14n2/. Acesso em: 22 fev. 2014.

SILVA, Mariana Cesar Verçosa; MELETTI, Silvia Márcia Ferreira. Estudantes com necessidades educacionais especiais nas avaliações em larga escala: prova Brasil e ENEM. Revista Brasileira de Educação Especial, São Paulo, n. 1, vol. 20, jan./mar. 2014. Disponível em: https://www.scielo.br/j/rbee/i/2014.v20n1/. Acesso em: 22 abr. 2014.

WILLIAMS, Lucia Cavalcanti de Albuquerque. Sobre deficiência e violência: reflexões para uma análise de revisão de área. Revista Brasileira de Educação Especial, São Paulo, n. 2, vol. 9, jul./ dez. 2003. Disponível em: https://www.abpee.net/pdf/artigos/art-9-2-2.pdf. Acesso em: 13 mar. 2014.

WILLIAMS, Raymond. Marxismo y literatura. 1 ed. Buenos Aires: Las Cuarenta, 2009. 